\title{
The Structure of Modified Fe-Ni Bioxide Composite Nanoparticles Using $\mathrm{Fe}\left(\mathrm{NO}_{3}\right)_{3}$
}

\author{
Yueqiang Lin ${ }^{1}$, Jian $\mathrm{Li}^{{ }^{*}}$, Lihua Lin ${ }^{1}$, Xiaodong Liu ${ }^{1}$, Longlong Chen ${ }^{1}$, Decai $\mathrm{Li}^{2}$ \\ ${ }^{1}$ School of Physical Science \& Technology, Southwest University, Chongqing, China \\ ${ }^{2}$ School of Mechanical and Control Engineering, Beijing Jiaotong University, Beijing, China \\ Email: *aizhong@swu.edu.cn
}

Received June 27, 2013; revised August 26, 2013; accepted September 11, 2013

Copyright (C) 2013 Yueqiang Lin et al. This is an open access article distributed under the Creative Commons Attribution License, which permits unrestricted use, distribution, and reproduction in any medium, provided the original work is properly cited.

\begin{abstract}
Composite nanoparticles containing a $\gamma-\mathrm{Fe}_{2} \mathrm{O}_{3}$ core, $\mathrm{Ni}_{2} \mathrm{O}_{3}$ external shell and $\mathrm{FeCl}_{3} \cdot 6 \mathrm{H}_{2} \mathrm{O}$ outermost layer can be synthesized by chemically induced transition in $\mathrm{FeCl}_{2}$ solution. These may be modified by treatment with $\mathrm{Fe}\left(\mathrm{NO}_{3}\right)_{3}$ to obtain particles for the preparation of ionic ferrofluids. Vibrating sample magnetometer (VSM) measurements and transmission electron microscopy (TEM) observations show that after $\mathrm{Fe}\left(\mathrm{NO}_{3}\right)_{3}$ treatment, the specific magnetization becomes weaker and the size becomes larger for treated particles compared with the untreated particles. Using energy dispersive X-ray spectroscopy (EDX), X-ray diffraction (XRD) and X-ray photoelectron spectroscopy (XPS), the structure of the particles before and after the treatment is revealed. The experimental results show that the $\gamma-\mathrm{Fe}_{2} \mathrm{O}_{3}$ core is unchanged, the $\mathrm{Ni}_{2} \mathrm{O}_{3}$ is dissolved partially and the $\mathrm{FeCl}_{3} \cdot 6 \mathrm{H}_{2} \mathrm{O}$ is replaced by $\mathrm{Fe}\left(\mathrm{NO}_{3}\right)_{3} \cdot 9 \mathrm{H}_{2} \mathrm{O}$. The percentages of molar, mass and volume of these phases are deduced, and the average density of the modified particles is also estimated.
\end{abstract}

Keywords: Nanoparticles; Composite; Treatment; Characterization

\section{Introduction}

Magnetic nanoparticles are an important class of nanoscopic magnetic systems. The preparation and characterization of magnetic nanoparticles have attracted increasing interest as particles in this size range may allow investigation of fundamental aspects of magnetic-ordering phenomena in magnetic materials with reduced dimension and could lead to new technological applications [1,2]. A nanocomposite is a material composed of two or more phases in which the combination of different physical or chemical properties may lead to completely novel materials [3]. In addition, magnetic nanocomposites have applications that range from ferrofluids to separation science and technology [4].

Ferrofluids (magnetic fluids) can be synthesized by dispersing nanosized subdomain magnetic particles of $\sim 10 \mathrm{~nm}$ in diameter in a carrier liquid. Generally, magnetic nanoparticles in ferrofluids are coated with a surfactant to prevent aggregation [5]. In the 1980s, Massart proposed a method for chemical synthesis of ferrofluids with no surfactant [6]. This method has subsequently

${ }^{*}$ Corresponding author. been called the Massart's method and such ferrofluids are known as ionic ferrofluids or electrical double-layered ferrofluids $[7,8]$. In an adaptation of Massart's method for the synthesis of the ferrofluids, magnetic nanoparticles need to be treated with ferric nitrate to yield a chemically stable particle surface.

Magnetization (moment per unit volume) $\mathrm{M}$ is an important physical parameter used to characterize magnetic materials. In practice, the volume of a particle $\mathrm{Vp}$ is too difficult to measure directly, so the magnetization is obtained usually from $M=\sigma \cdot \rho$, where $\sigma$ is the specific magnetization (moment per unit mass) and $\rho$ is the known density of the constituent materials [9]. In addition, the volume fraction of particles in ferrofluids, $\phi_{\mathrm{v}}=$ $\mathrm{Vp} /(\mathrm{Vp}+\mathrm{Vc})$, where $\mathrm{Vp}$ is the volume of the particles and $\mathrm{Vc}$ is the volume of the carrier liquid, is also an important characteristic parameter to which the behavior of ferrofluids is related [10]. Therefore, volume of the particles is an important feature for magnetic nanoparticles and is generally obtained from an accurate measure of the mass $\mathrm{m}$ and the known density $\rho$, i.e. $\mathrm{Vp}=\mathrm{m} / \rho$. However, if the nanoparticles consist of different chemical compounds, the density of the particles is no longer 
uniform, and their volume cannot be determined by measuring just their mass.

Recently, we have proposed a method to prepare Fe-Ni bioxide composite nanoparticles by a chemically induced transition [11]. These nanoparticles might be very suitable for the synthesis of ionic ferrofluids [12]. In the present work, untreated Fe-Ni bioxide composite nanoparticles and those treated with ferric nitrate have been characterized, and their chemical compositions and average density were studied.

\section{Experimental}

The $\gamma-\mathrm{Fe}_{2} \mathrm{O}_{3} / \mathrm{Ni}_{2} \mathrm{O}_{3}$ composite nanoparticles were prepared by the so-called chemically induced transition method. The preparation can be divided into two steps. Firstly, an aqueous mixture of $\mathrm{FeCl}_{3}(40 \mathrm{ml}, 1 \mathrm{M})$ and $\mathrm{Ni}\left(\mathrm{NO}_{3}\right)_{3}(10 \mathrm{ml}, 2 \mathrm{M}$; in $\mathrm{HCl} 0.05 \mathrm{ml})$ was added to $\mathrm{NaOH}$ solution $(500 \mathrm{ml}, 0.7 \mathrm{M})$. Then the solution was heated and boiled for $5 \mathrm{~min}$, after which the black precursor gradually precipitated. Secondly, the precursor was added to $\mathrm{FeCl}_{2}$ solution $(400 \mathrm{ml}, 0.25 \mathrm{M})$, which was then heated to boiling point for $30 \mathrm{~min}$. The nanoparticles were again precipitated after the heating had stopped. After washing to $\mathrm{pH}=7$ with very dilute aqueous $\mathrm{HNO}_{3}$ solution $(\leq 0.01 \mathrm{M})$, the as-prepared particles (the untreated particles) were added to boiling $\mathrm{Fe}\left(\mathrm{NO}_{3}\right)_{3}$ solution $(400 \mathrm{ml}, 0.25 \mathrm{M})$, which was then kept boiling for $30 \mathrm{~min}$. The particles were then dehydrated with acetone and allowed to dry naturally to yield the modified particles (the treated particles).

The magnetization, morphology, bulk chemical species, crystal structure and surface chemical compositions of the particles were investigated using a vibrating sample magnetometer (VSM, HH-15), transmission electron microscopy (TEM, TecnaiG220), energy dispersive Xray spectroscopy (EDX, Quanta-200), X-ray diffraction (XRD, XD-12) and X-ray photoelectron spectroscopy (XPS, SAM800). The phase structures of the particles were determined from the experimental results.

\section{Results and Analysis}

The specific magnetization curves are shown in Figure 1. Clearly, the magnetization of the treated particles is weaker than that of the untreated particles. From the plots of $\sigma$ vs. $1 / \mathrm{H}$ in high field [13] the specific saturation magnetizations $\sigma_{\mathrm{s}}$ are evaluated as $56.59 \mathrm{emu} / \mathrm{g}$ and $41.19 \mathrm{emu} / \mathrm{g}$ for the untreated and treated particles, respectively.

TEM observations show that both untreated and treated particles were spherical. Figure 2 is a typical TEM micrograph of the particles. Statistical analysis reveals that the size of the particles fits a log-normal distribution. For the untreated particles, the median diameter

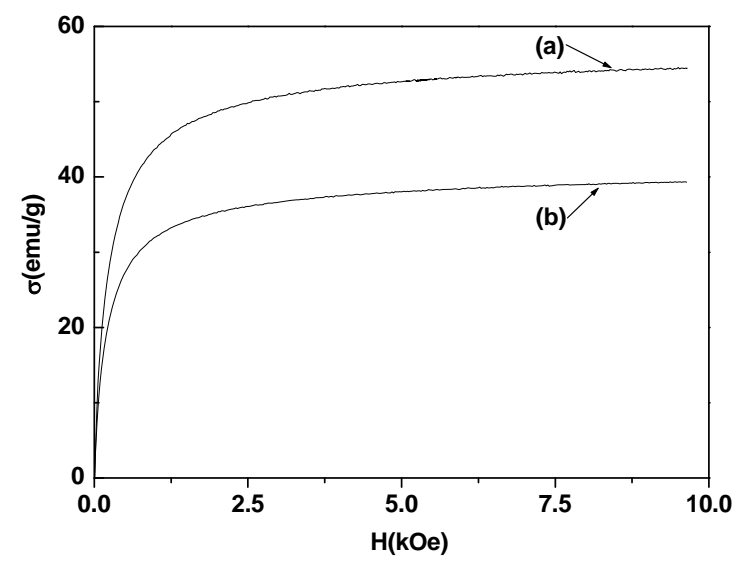

Figure 1. The specific magnetization curves of (a) untreated particles and (b) treated particles.
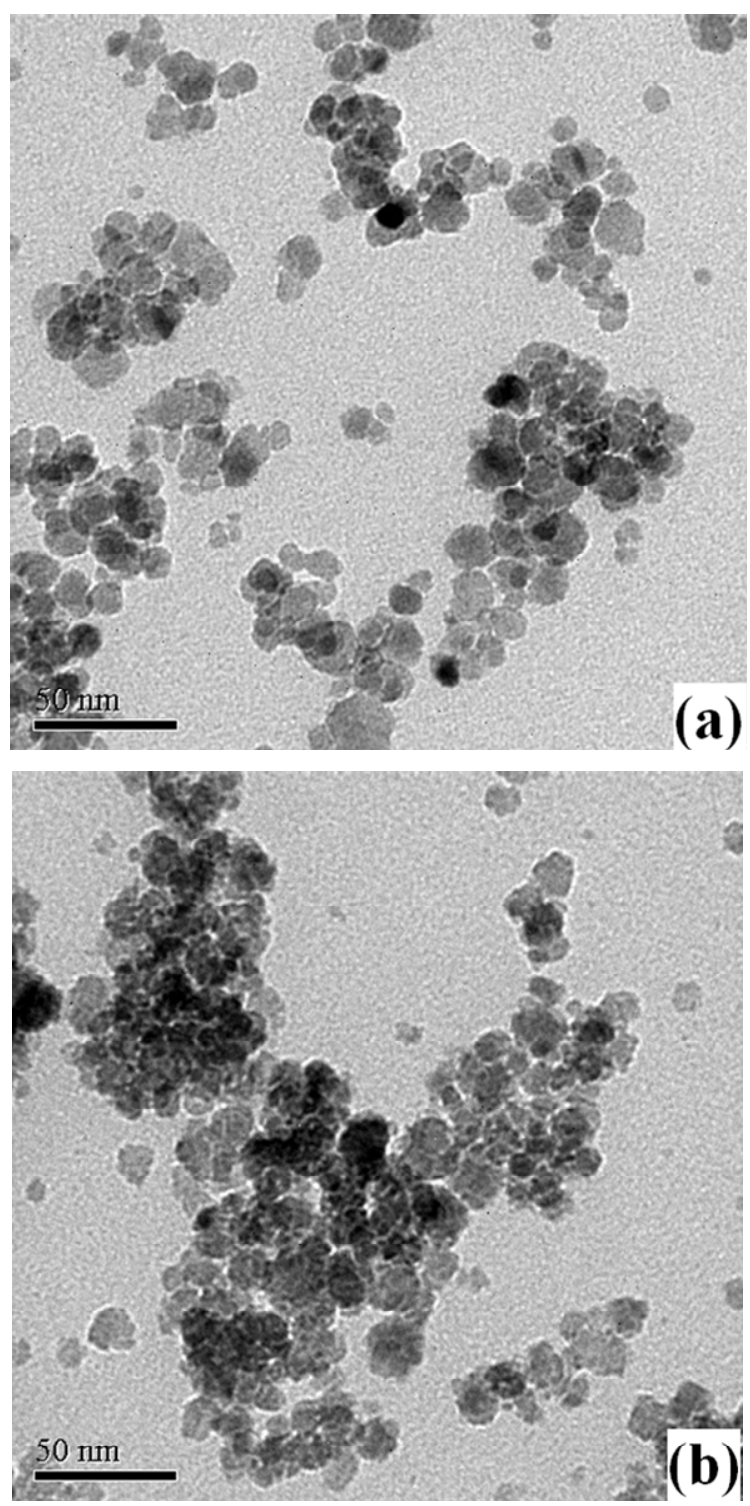

Figure 2. Typical TEM images of (a) untreated particles and (b) treated particles. 
$\mathrm{dg}$ is $10.78 \mathrm{~nm}$ and the standard deviation $\ln \sigma_{\mathrm{g}}$ is 0.27 ; for the treated particles, $\mathrm{dg}$ is $11.43 \mathrm{~nm}$ and $\ln \sigma_{\mathrm{g}}$ is 0.26 . The average diameter $<\mathrm{d}>$ is calculated from $<\mathrm{d}>=\exp$ $\left[\operatorname{lndg}+0.5 \ln ^{2} \sigma_{\mathrm{g}}\right]$ [14] and gives.11.18 nm for the untreated particles, and $11.82 \mathrm{~nm}$ for the treated particles.

The results of the EDX measurements indicated that both untreated and treated particles had $\mathrm{O}, \mathrm{Fe}$ and $\mathrm{Ni}$ species, but the untreated particles also contained $\mathrm{Cl}$ and the treated particles contained $\mathrm{N}$ and $\mathrm{Cl}$. The atomic percentages $\mathrm{a}_{\mathrm{i}}$ for these elements are listed in Table $\mathbf{1}$

Figure 3 shows the XRD patterns for the two nanoparticles. For the untreated particles, the major diffraction peaks corresponded to $\gamma-\mathrm{Fe}_{2} \mathrm{O}_{3}$ (magnetite, $\mathrm{PDF} \#$ 39-1346), with some weaker peaks corresponding to $\mathrm{Ni}_{2} \mathrm{O}_{3}$ (PDF\#14-0481). No clear diffraction peaks corresponded to any phase based on the $\mathrm{Cl}$ species. In addition, for the treated particles, diffraction peaks were present for both $\gamma-\mathrm{Fe}_{2} \mathrm{O}_{3}$ and $\mathrm{Ni}_{2} \mathrm{O}_{3}$. However, by comparing with the pattern of untreated particles, it was found that the diffraction intensity of $\mathrm{Ni}_{2} \mathrm{O}_{3}$ had been weakened relative to that of $\gamma-\mathrm{Fe}_{2} \mathrm{O}_{3}$. In addition, some new diffraction peaks appeared, as indicated by arrows A, B, C and D. These are close to the $\mathrm{d}=0.2620,0.2550,0.1900$ and $0.1700 \mathrm{~nm}$ peaks of $\mathrm{Fe}\left(\mathrm{NO}_{3}\right)_{3} \cdot 9 \mathrm{H}_{2} \mathrm{O}$ (PDF\#01-0124).

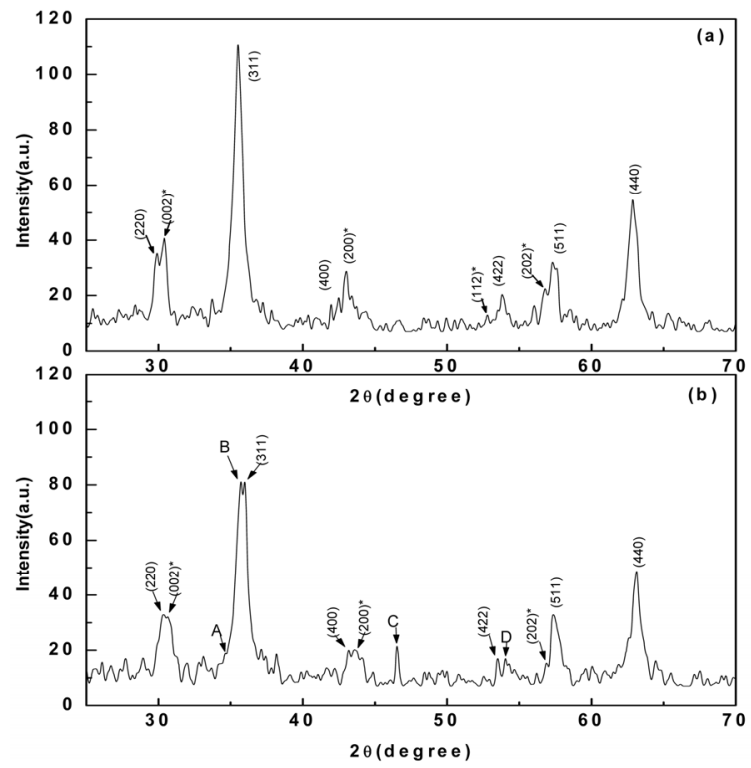

Figure 3. XRD patterns of (a) untreated particles and (b) treated particles. The peaks (h $\mathrm{k}$ l) correspond to $\gamma-\mathrm{Fe}_{2} \mathrm{O}_{3}$ (PDF\#39-1346) and peaks (h $\mathrm{k} \mathrm{l}$ ) ${ }^{*}$ correspond to $\mathrm{Ni}_{2} \mathrm{O}_{3}$ (PDF\#14-0481).

Table 1. The atomic composition from EDX measurement $\mathbf{a}_{\mathbf{i}}$.

\begin{tabular}{cccccc}
\hline $\mathrm{i}$ & $\mathrm{O}$ & $\mathrm{Fe}$ & $\mathrm{Ni}$ & $\mathrm{Cl}$ & $\mathrm{N}$ \\
\hline Untreated particles & 56.82 & 39.15 & 2.37 & 1.66 & \\
Treated particles & 60.33 & 35.60 & 1.57 & & 2.50 \\
\hline
\end{tabular}

The XPS spectra are shown in Figure 4. These confirm the presence of the same chemical species as determined by the EDX measurements. Combining the EDX and XRD results, it was apparent that besides $\gamma-\mathrm{Fe}_{2} \mathrm{O}_{3}$ and $\mathrm{Ni}_{2} \mathrm{O}_{3}$, there was also a phase based on $\mathrm{Cl}$ in the untreated particles and $\mathrm{Fe}\left(\mathrm{NO}_{3}\right)_{3} \cdot 9 \mathrm{H}_{2} \mathrm{O}$ was present in the treated particles. As a result, the $\mathrm{O} 1 \mathrm{~s}$ and $\mathrm{Fe} 2 \mathrm{p} 3 / 2$ lines are split, as shown in Figure 5. The detailed binding energy data are listed in Table 2. To summarize, these measurements precisely identify $\gamma-\mathrm{Fe}_{2} \mathrm{O}_{3}, \mathrm{Ni}_{2} \mathrm{O}_{3}$ and $\mathrm{FeCl}_{3}$ phases in the untreated particles and $\gamma-\mathrm{Fe}_{2} \mathrm{O}_{3}$, $\mathrm{Ni}_{2} \mathrm{O}_{3}$ and $\mathrm{Fe}\left(\mathrm{NO}_{3}\right)_{3} \cdot 9 \mathrm{H}_{2} \mathrm{O}$ phases in treated particles. In the untreated particles, the $\mathrm{FeCl}_{3}$ phase could contain

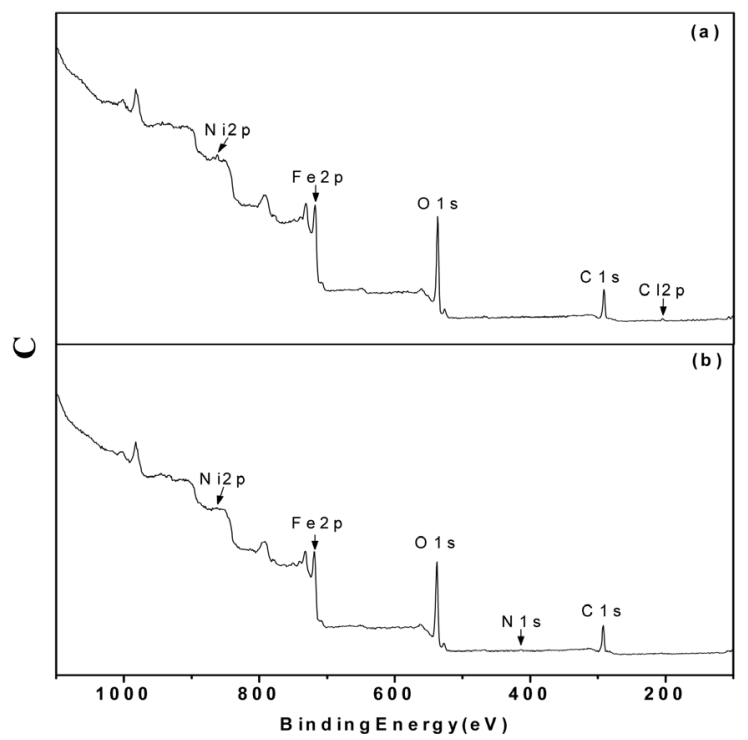

Figure 4. XPS spectra of (a) untreated particles and (b) treated particles.

Table 2. The binding energy data from XPS measurements (eV).

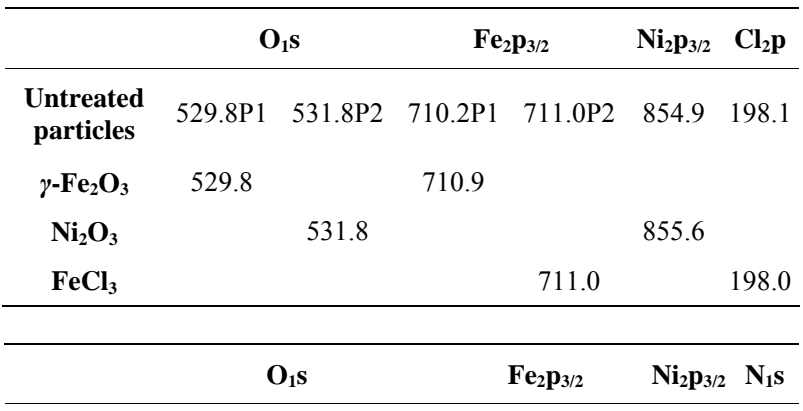

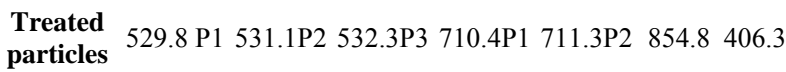

$\begin{array}{lll}\boldsymbol{\gamma}-\mathrm{Fe}_{2} \mathbf{O}_{3} & 529.8 & 710.9\end{array}$

$\mathbf{N i}_{2} \mathbf{O}_{3} \quad 531.8 \quad 855.6$

$\begin{array}{llll}\mathbf{F e}\left(\mathrm{NO}_{3}\right)_{3} & 532.93 & 710.09 & 406.7\end{array}$

Note: The standard data for $\gamma-\mathrm{Fe}_{2} \mathrm{O}_{3}, \mathrm{Ni}_{2} \mathrm{O}_{3}, \mathrm{FeCl}_{3}$ are taken from the Handbook of X-ray photoelectron spectroscopy. Data for $\mathrm{Fe}\left(\mathrm{NO}_{3}\right)_{3} \cdot 9 \mathrm{H}_{2} \mathrm{O}$ are taken from Ref. [16]. 

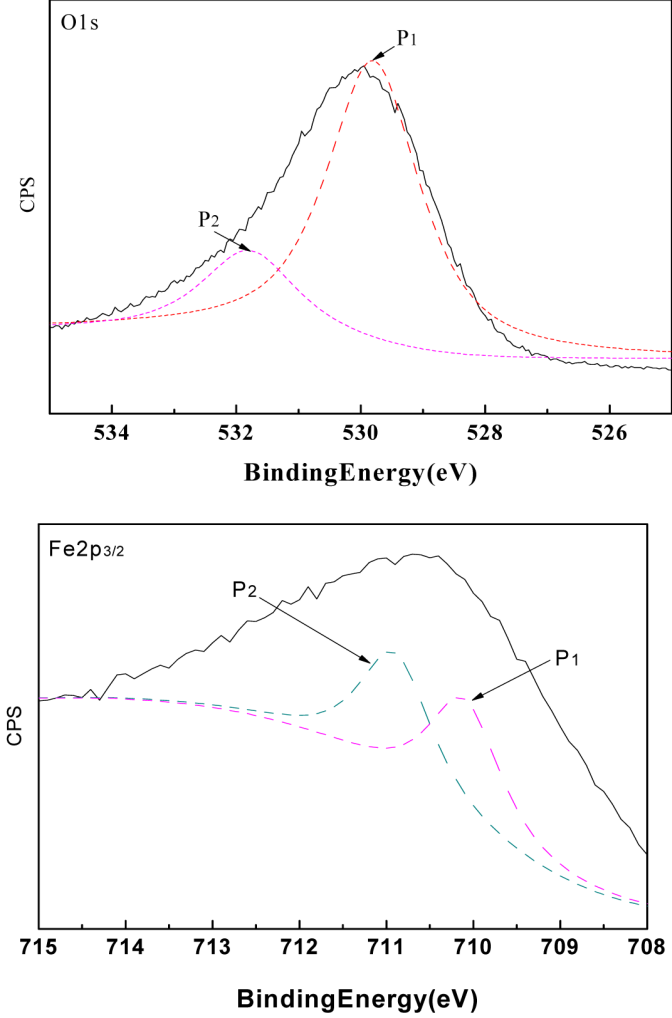

(a)
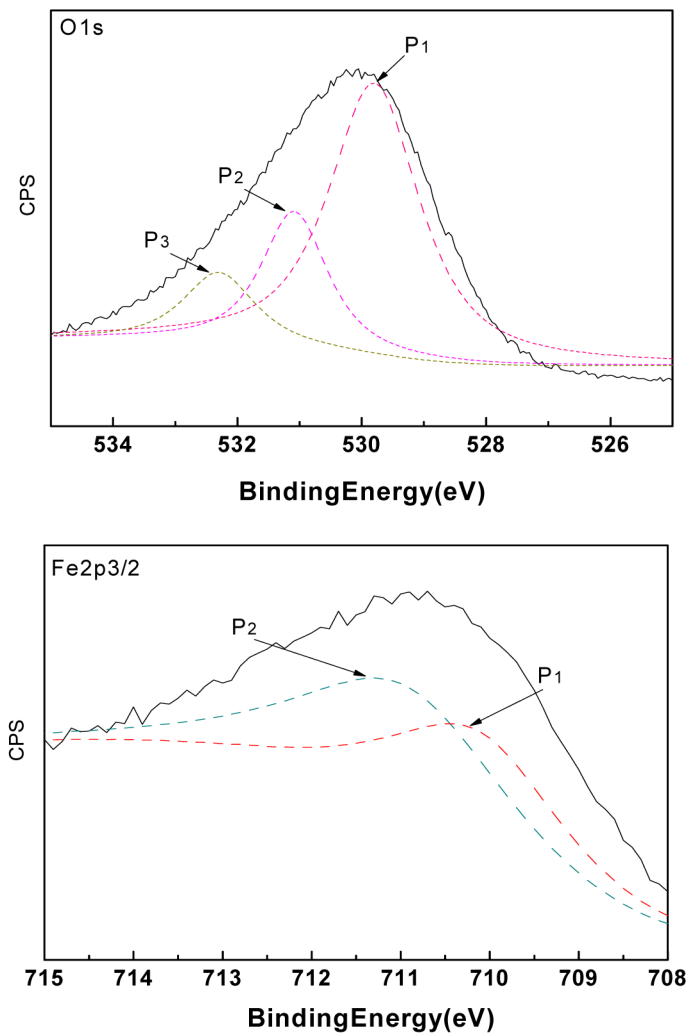

(b)

Figure 5. XPS results of $\mathrm{O}_{1} \mathrm{~s}$ lines and $\mathrm{Fe} \mathrm{Fe}_{2} \mathrm{p}_{3 / 2}$ lines for (a) untreated particles and (b) treated particles. water of crystallization, as in $\mathrm{FeCl}_{3} \cdot 6 \cdot \mathrm{H}_{2} \mathrm{O}$, since this compound is formed on the $\gamma-\mathrm{Fe}_{2} \mathrm{O}_{3}$ cores, when these are synthesized by a similar, chemically induced transition method in $\mathrm{FeCl}_{2}$ solution [15].

\section{Discussion}

\subsection{The Structure of the Particles}

The experimental results and analysis above reveal that both untreated and treated particles are spherical nanoparticles with sizes of the order of $10 \mathrm{~nm}$. The untreated particles consist of $\gamma-\mathrm{Fe}_{2} \mathrm{O}_{3}, \mathrm{Ni}_{2} \mathrm{O}_{3}$ and $\mathrm{FeCl}_{3} \cdot 6 \mathrm{H}_{2} \mathrm{O}$ phases. There must be very little $\mathrm{FeCl}_{3} \cdot 6 \mathrm{H}_{2} \mathrm{O}$ since there were no clear corresponding diffraction peaks in the XRD pattern. In addition, in the treated particles, $\mathrm{Fe}\left(\mathrm{NO}_{3}\right)_{3} \cdot 9 \mathrm{H}_{2} \mathrm{O}$ is present as well as the $\gamma-\mathrm{Fe}_{2} \mathrm{O}_{3}$ and $\mathrm{Ni}_{2} \mathrm{O}_{3}$ phases, but no $\mathrm{FeCl}_{3} \cdot 6 \mathrm{H}_{2} \mathrm{O}$. Comparing with the untreated particles, the proportion of $\mathrm{Ni}_{2} \mathrm{O}_{3}$ is lower in the treated particles. We conclude that during the treatment, $\mathrm{FeCl}_{3} \cdot 6 \mathrm{H}_{2} \mathrm{O}$ and some $\mathrm{Ni}_{2} \mathrm{O}_{3}$ are dissolved and $\mathrm{Fe}\left(\mathrm{NO}_{3}\right)_{3} \cdot 9 \mathrm{H}_{2} \mathrm{O}$ is formed instead. As a consequence, it appears that the untreated nanoparticles consist of a $\gamma$ - $\mathrm{Fe}_{2} \mathrm{O}_{3}$ core, $\mathrm{Ni}_{2} \mathrm{O}_{3}$ external shell and $\mathrm{FeCl}_{3} \cdot 6 \mathrm{H}_{2} \mathrm{O}$ outermost layer; the treated particles have the same core and external shell, but $\mathrm{Fe}\left(\mathrm{NO}_{3}\right)_{3} \cdot 9 \mathrm{H}_{2} \mathrm{O}$ outermost layer. A schematic structural diagram of the particles is presented in Figure 6. It appears that the $\gamma-\mathrm{Fe}_{2} \mathrm{O}_{3}$ core remains unchanged when the particles are treated in $\mathrm{Fe}\left(\mathrm{NO}_{3}\right)_{3}$ solution.

\subsection{The Molar Percentages of the Phases in the Particles}

The structural data and the quantitative elemental analysis from the EDX measurements provide a description of the molar ratios of the phases for both particles, as follows.

For the untreated particles, based on $\gamma-\mathrm{Fe}_{2} \mathrm{O}_{3}, \mathrm{Ni}_{2} \mathrm{O}_{3}$ and $\mathrm{FeCl}_{3} \cdot 6 \mathrm{H}_{2} \mathrm{O}$ phases, the molar ratio between the $\gamma-\mathrm{Fe}_{2} \mathrm{O}_{3}$ and $\mathrm{Ni}_{2} \mathrm{O}_{3}$ phases, $\mathrm{y}_{\gamma / \mathrm{Ni}}$, can be written as

$$
y_{\gamma / \mathrm{Ni}}=\frac{y_{\gamma}\left(\gamma-\mathrm{Fe}_{2} \mathrm{O}_{3}(\mathrm{~mol})\right)}{y_{\mathrm{Ni}}\left(\mathrm{Ni}_{2} \mathrm{O}_{3}(\mathrm{~mol})\right)} \frac{a_{\mathrm{Cl}}}{a_{\mathrm{Ni}}}\left(\frac{a_{\mathrm{Fe}}}{a_{\mathrm{Cl}}}-\frac{1}{3}\right)
$$

where $a_{\mathrm{Fe}}, a_{\mathrm{Ni}}$ and $a_{\mathrm{Cl}}$ are the atomic percentages of $\mathrm{Fe}$, $\mathrm{Ni}$ and $\mathrm{Cl}$, respectively. Likewise, the ratio between the

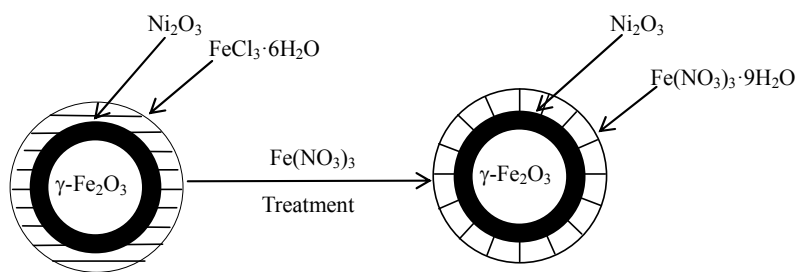

Figure 6. Schematic model of the structures of the particles. 
$\gamma-\mathrm{Fe}_{2} \mathrm{O}_{3}$ and $\mathrm{FeCl}_{3}$ phases, $y_{\gamma / \mathrm{Cl}}$, can be written as

$$
y_{\gamma / \mathrm{Cl}}=\frac{y_{\gamma}\left(\gamma-\mathrm{Fe}_{2} \mathrm{O}_{3}(\mathrm{~mol})\right)}{y_{\mathrm{Cl}}\left(\mathrm{FeCl}_{3}(\mathrm{~mol})\right)}=\frac{3}{2}\left(\frac{a_{\mathrm{Fe}}}{a_{\mathrm{Cl}}}-\frac{1}{3}\right)
$$

Consequently, the molar percentages of $\gamma-\mathrm{Fe}_{2} \mathrm{O}_{3}\left(y_{\gamma}\right)$, $\mathrm{Ni}_{2} \mathrm{O}_{3}\left(y_{\mathrm{Ni}}\right)$ and $\mathrm{FeCl}_{3}\left(y_{\mathrm{Cl}}\right)$ can be obtained as

$$
y_{\gamma}=\frac{1}{1+\frac{1}{y_{\gamma / \mathrm{Ni}}}+\frac{1}{y_{\gamma / \mathrm{Cl}}}} \times 100, y_{\mathrm{Ni}}=\frac{y_{\gamma}}{y_{\gamma / \mathrm{Ni}}}, y_{\mathrm{Cl}}=\frac{y_{\gamma}}{y_{\gamma / \mathrm{Cl}}}
$$

From the EDX data listed in Table 1, the values of $y_{\gamma}, y_{\mathrm{Ni}}$ and $y_{\mathrm{Cl}}$ can be calculated and these are given in Table 3.

For the treated particles based on $\gamma-\mathrm{Fe}_{2} \mathrm{O}_{3}, \mathrm{Ni}_{2} \mathrm{O}_{3}$ and $\mathrm{Fe}\left(\mathrm{NO}_{3}\right)_{3} \cdot 9 \mathrm{H}_{2} \mathrm{O}$ phases, $y_{\gamma / \mathrm{Ni}}$, can be written as

$$
y_{\gamma / \mathrm{Ni}}=\frac{y_{\gamma}\left(\gamma-\mathrm{Fe}_{2} \mathrm{O}_{3}(\mathrm{~mol})\right)}{y_{\mathrm{Ni}}\left(\mathrm{Ni}_{2} \mathrm{O}_{3}(\mathrm{~mol})\right)}=\frac{a_{\mathrm{N}}}{a_{\mathrm{Ni}}}\left(\frac{a_{\mathrm{Fe}}}{a_{\mathrm{N}}}-\frac{1}{3}\right)
$$

where $a_{\mathrm{Fe}}, a_{\mathrm{Ni}}$ and $a_{\mathrm{N}}$ are the atomic percentages of Fe, $\mathrm{Ni}$ and $\mathrm{N}$, respectively. Likewise, the ratio between $\gamma-\mathrm{Fe}_{2} \mathrm{O}_{3}$ and $\mathrm{Fe}\left(\mathrm{NO}_{3}\right)_{3}$ phases, $y_{\gamma / \mathrm{N}}$, can be written as

$$
y_{\gamma / \mathrm{N}}=\frac{y_{\gamma}\left(\gamma-\mathrm{Fe}_{2} \mathrm{O}_{3}(\mathrm{~mol})\right)}{y_{\mathrm{N}}\left(\mathrm{FeCl}_{3}(\mathrm{~mol})\right)}=\frac{3}{2}\left(\frac{a_{\mathrm{Fe}}}{a_{\mathrm{N}}}-\frac{1}{3}\right)
$$

Thus, the molar percentages of $\gamma-\mathrm{Fe}_{2} \mathrm{O}_{3}\left(y_{\gamma}\right)$, $\mathrm{Ni}_{2} \mathrm{O}_{3}\left(y_{\mathrm{Ni}}\right)$ and $\mathrm{Fe}\left(\mathrm{NO}_{3}\right)_{3}\left(y_{\mathrm{N}}\right)$ for the treated particles, can be obtained from

$$
y_{\gamma}=\frac{1}{1+\frac{1}{y_{\gamma / \mathrm{Ni}}}+\frac{1}{y_{\gamma / \mathrm{N}}}} \times 100, y_{\mathrm{Ni}}=\frac{y_{\gamma}}{y_{\gamma / \mathrm{Ni}}}, y_{\mathrm{N}}=\frac{y_{\gamma}}{y_{y_{\gamma / \mathrm{N}}}}
$$

The values of $y_{\gamma}, y_{\mathrm{Ni}}$ and $y_{\mathrm{N}}$ can be calculated from the data listed in Table 1, and are also listed in Table 3. Clearly, the $y_{\gamma / \mathrm{Ni}}$ value of the treated particles (91.48/4.17) is larger than that of the untreated particles (91.74/5.63), which confirms the reduction of the $\mathrm{Ni}_{2} \mathrm{O}_{3}$ phase after the treatment, since the molar concentrations of $\gamma-\mathrm{Fe}_{2} \mathrm{O}_{3}$ in both untreated and treated particles can be regarded as equal.

\subsection{The Mass Percentages of the Phases in the Particles}

From the molar percentage of each phase, the mass percentages of the phases in both untreated and treated particles, $z_{i}$, can be deduced from

$$
z_{i}=\frac{y_{i} A_{i}}{\sum y_{i} A_{i}} \times 100
$$

where $y_{i}$ is the molar percentage and $A_{i}$ is molecular weight of the $i$ phase in the particles. Accordingly, the mass percentage of each phase for the two particles can
Table 3. The molar percentage of each phases in the untreated and treated particles $y_{i}$.

\begin{tabular}{ccccc}
\hline$i$ & $\gamma-\mathrm{Fe}_{2} \mathrm{O}_{3}$ & $\mathrm{Ni}_{2} \mathrm{O}_{3}$ & $\mathrm{FeCl}_{3}$ & $\mathrm{Fe}\left(\mathrm{NO}_{3}\right)_{3}$ \\
\hline Untreated particles & 91.74 & 5.63 & 2.63 & \\
treated particles & 91.48 & 4.14 & & 4.38 \\
\hline
\end{tabular}

be obtained from the results listed in Table 3 and the molecular weights of $\gamma-\mathrm{Fe}_{2} \mathrm{O}_{3}, \mathrm{Ni}_{2} \mathrm{O}_{3}, \mathrm{FeCl}_{3} \cdot 6 \mathrm{H}_{2} \mathrm{O}$ or $\mathrm{Fe}\left(\mathrm{NO}_{3}\right)_{3} \cdot 9 \mathrm{H}_{2} \mathrm{O}$, which are listed in Table 4 .

From the results in Table 4, it can be seen that the mass fractions of both $\gamma-\mathrm{Fe}_{2} \mathrm{O}_{3}$ and $\mathrm{Ni}_{2} \mathrm{O}_{3}$ in the treated particles are less than in the untreated particles. Therefore, the specific magnetization of the former is weaker than that of the latter, since $\gamma-\mathrm{Fe}_{2} \mathrm{O}_{3}$ is ferrimagnetic, $\mathrm{Ni}_{2} \mathrm{O}_{3}$ is weakly ferromagnetic [16], and both $\mathrm{FeCl}_{3}$ and $\mathrm{Fe}\left(\mathrm{NO}_{3}\right)_{3}$ are paramagnetic.

\subsection{The Volume Percentages of the Phases in the Particles}

From the mass percentage $z_{i}$, the volume percentage of each phase in the particle system, $\phi_{i}$, can be obtained from

$$
\phi_{i}=\frac{z_{i} / \rho_{i}}{\sum z_{i} / \rho_{i}} \times 100
$$

where $\phi_{i}$ is the density of the $i$ phase. The densities of $\gamma-\mathrm{Fe}_{2} \mathrm{O}_{3}, \mathrm{Ni}_{2} \mathrm{O}_{3}, \quad \mathrm{FeCl}_{3} \cdot 6 \mathrm{H}_{2} \mathrm{O}$ and $\mathrm{Fe}\left(\mathrm{NO}_{3}\right)_{3} \cdot 9 \mathrm{H}_{2} \mathrm{O}$ are $4.90,5.32,1.844$ and $1.684 \mathrm{~g} / \mathrm{cm}^{3}$, respectively. Thus, from the $z_{i}$ values listed in Table 4, the values of $\phi_{i}$ can be calculated, and are listed in Table 5. For the treated particles, the volume of the $\gamma-\mathrm{Fe}_{2} \mathrm{O}_{3}$ phase should be same as for the untreated ones. The fact that the volume percentage of $\gamma-\mathrm{Fe}_{2} \mathrm{O}_{3}$ phase for the treated particles is less than that for the untreated particles shows that the size of the former is larger than that of the latter. This is in agreement with the TEM results.

\subsection{The Density of the Particles}

From both mass percentages and densities of each phase, the average density of the particles containing many phases, $\langle\rho\rangle$, can be obtained from

$$
\langle\rho\rangle=\frac{\sum \rho_{i} \phi_{i}}{100}=\frac{1}{\sum z_{i} / \rho_{i}} \times 100
$$

Using Formula (9), the average density can be estimated as $4.596 \mathrm{~g} / \mathrm{cm}^{3}$ and $4.102 \mathrm{~g} / \mathrm{cm}^{3}$ for the untreated and treated particles, respectively. For the treated particles, the density $4.102 \mathrm{~g} / \mathrm{cm}^{3}$ is very close to $4.125 \mathrm{~g} / \mathrm{cm}^{3}$, which was deduced from density measurements of the corresponding ferrofluids [12].

From the average density, the magnetization curves of 
$\mathrm{M}\left(=\sigma_{\mathrm{i}} \rho_{\mathrm{i}}\right)$ vs. $\mathrm{H}$ can be obtained from the specific magnetization, as shown in Figure 7. The values of saturation magnetization $\mathrm{M}_{\mathrm{s}}\left(=\sigma_{\mathrm{s}} \cdot<\rho>\right)$ were obtained from $\sigma_{\mathrm{s}}$ as 260.09 and $168.96 \mathrm{kA} / \mathrm{m}$ for the untreated and treated particles, respectively.

\section{Conclusion}

Using a chemically induced transition in $\mathrm{FeCl}_{2}$ solution, composite nanoparticles containing a $\gamma-\mathrm{Fe}_{2} \mathrm{O}_{3}$ core, $\mathrm{Ni}_{2} \mathrm{O}_{3}$ shell and $\mathrm{FeCl}_{3} \cdot 6 \mathrm{H}_{2} \mathrm{O}$ outermost layer, were synthesized. The $\mathrm{Fe}\left(\mathrm{NO}_{3}\right)_{3}$ solution treatment after synthesis dissolves $\mathrm{FeCl}_{3}$ and some of the $\mathrm{Ni}_{2} \mathrm{O}_{3}$ to give a new $\mathrm{Fe}\left(\mathrm{NO}_{3}\right)_{3} \cdot 9 \mathrm{H}_{2} \mathrm{O}$ layer on the undissolved part of the nanoparticles. This shows that during the $\mathrm{Fe}\left(\mathrm{NO}_{3}\right)_{3}$ treatment, it is easily absorbed on the ferrite particles to form a $\mathrm{Fe}\left(\mathrm{NO}_{3}\right)_{3} \cdot 9 \mathrm{H}_{2} \mathrm{O}$ surface layer, a result similar to $\mathrm{Fe}_{3} \mathrm{O}_{4}$ when treated with $\mathrm{Fe}\left(\mathrm{NO}_{3}\right)_{3}[17,18]$. For the composite nanoparticles with many phases, combining bulk with surface analysis using EDX, XRD and XPS reveals their structure and the molar, mass and volume percentages of each phase can be calculated. As a consequence,

Table 4. The mass percentage of each phases in the untreated and treated particles $\mathrm{z}_{\mathbf{i}}$.

\begin{tabular}{cccc}
\hline $\mathrm{i}$ & $\gamma-\mathrm{Fe}_{2} \mathrm{O}_{3}$ & $\mathrm{Ni}_{2} \mathrm{O}_{3}$ & $\mathrm{FeCl}_{3} \cdot 6 \mathrm{H}_{2} \mathrm{O} \mathrm{Fe}\left(\mathrm{NO}_{3}\right)_{3} \cdot 9 \mathrm{H}_{2} \mathrm{O}$ \\
\hline Untreated particles & 90.01 & 5.72 & 4.27 \\
Treated particles & 85.62 & 4.01 & \\
\hline
\end{tabular}

Table 5. The percentage volume of each phases in the untreated and treated particles $\phi_{i}$.

\begin{tabular}{ccccc}
\hline$i$ & $\gamma-\mathrm{Fe}_{2} \mathrm{O}_{3}$ & $\mathrm{Ni}_{2} \mathrm{O}_{3}$ & $\begin{array}{r}\mathrm{FeCl}_{3} \cdot 6 \mathrm{H}_{2} \mathrm{Fe}\left(\mathrm{NO}_{3}\right)_{3} \cdot 9 \mathrm{H}_{2} \\
\mathrm{O}\end{array}$ & $\mathrm{O}$ \\
\hline Untreated particles & 84.42 & 4.94 & 10.64 & \\
Treated particles & 71.67 & 3.09 & & 25.24 \\
\hline
\end{tabular}

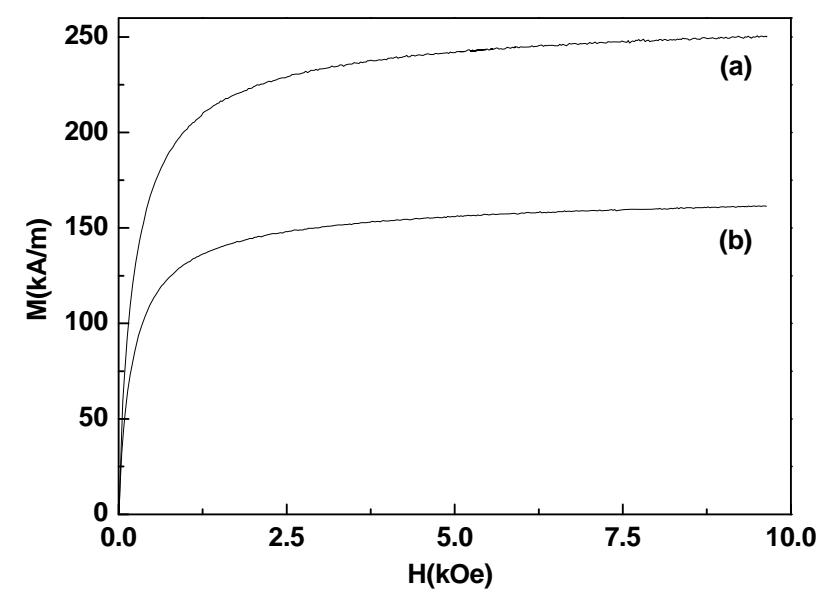

Figure 7. The magnetization curves of (a) untreated particles and (b) treated particles. the difference of both magnetization and size between the treated and untreated particles can be explained from the phase ratios. In addition, the average density of the particles can be obtained, which is very important for the synthesis of ferrofluids with accurate volume fractions of particles. The experiments indicated that after treatment with $\mathrm{Fe}\left(\mathrm{NO}_{3}\right)_{3}$, although the $\gamma-\mathrm{Fe}_{2} \mathrm{O}_{3}$ core is unchanged, the magnetization of the treated particles becomes much weaker than that of the untreated particles. Clearly, this is evidence showing that the surfaces of magnetic nanoparticles play an important role in determining their magnetization behavior.

\section{Acknowledgements}

Financial support for this work was provided by the Nature Science Foundation of China (11074205)

\section{REFERENCES}

[1] J. Nogués, J. Sort, V. Langlais, V. Skumryev, S. Suriñach, J. S. Muñoz, et al., "Exchange Bias in Nanostructures," Physics Reports-Review Section of Physics Letters, Vol. 422, No. 3, 2005, pp. 65-117.

[2] M. Knobel, W. C. Nunes, L. M. Socolovsky, E. De Biasi, J. M. Vargas and J. C. Denardin, "Superparamagnetism and Other Magnetic Features in Granular Materials: A Review on Ideal and Real Systems," Journal of Nanoscience and Nanotechnology, Vol. 8, No. 6, 2008, pp. 2836-2857.

[3] D. V. Szabó and D. Vollath, "Nanocomposites from Coated Nanoparticles," Advanced Materials, Vol. 11, No. 15, 1999, pp. 1313-1316.

http://dx.doi.org/10.1002/(SICI)1521-4095(199910)11:15 $\leq 1313::$ AID-ADMA1313>3.0.CO;2-2

[4] Q. X. Liu, Z. H. Xu, J. A. Finch and R. Egerton, “A Novel Two-Step Silica-Coating Process for Engineering Magnetic Nanocomposites," Chemistry of Materials, Vol. 10, No. 12, 1998, pp. 3936-3940. http://dx.doi.org/10.1021/cm980370a

[5] R. E. Rosensweig, "Ferrohydrodynamic," Cambrige University, Combridge, 1985.

[6] R. Massart, "Preparation of Aqueous Magnetic Liquids in Alkaline and Acidic Media," IEEE Transactions on Magnetics, Vol. 17, No. 2, 1981, pp. 1247-1248. http://dx.doi.org/10.1109/TMAG.1981.1061188

[7] F. A. Tourinho, R. Franck and R. Massart, "Aqueous Ferrofluids Based on Manganese and Cobalt Ferrites," Journal of Materials Science, Vol. 25, No. 7, 1990, pp. 3249-3254. http://dx.doi.org/10.1007/BF00587682

[8] M. H. Sousa, F. A. Tourinho, J. Depeyrot, G. J. da Silva and M. C. F. Lara, "New Electric Double-Layered Magnetic Fluids Based on Copper, Nickel, and Zinc Ferrite Nanostructures," The Journal of Physical Chemistry B, Vol. 105, No. 6, 2001, pp. 1168-1175. http://dx.doi.org/10.1021/jp0039161

[9] J. Crangle, "The Magnetic Properties of Solids," Edward Arnold, London, 1977. 
[10] B. Huke and M. Lücke, "Magnetic Properties of Colloidal Suspensions of Interacting Magnetic Particles," Reports on Progress in Physics, Vol. 67, No. 10, 2004, pp. 17311768. http://dx.doi.org/10.1088/0034-4885/67/10/R01

[11] Q. M. Zhang, J. Li, Y. Q. Lin, X. D. Liu and H. Miao, "The Preparation and Characterization of Ni-Fe Bioxide Composite Nanoparticles," Journal of Alloys and Compounds, Vol. 508, No. 2, 2010, pp. 396-399. http://dx.doi.org/10.1016/j.jallcom.2010.08.065

[12] L. H. Lin, J. Li, J. Fu, Y. Q. Lin and X. D. Liu, "Preparation, Magnetization, and Microstructure of Ionic Ferrofluids Based on Gamma- $\mathrm{Fe}_{2} \mathrm{O}_{3} / \mathrm{Ni}_{2} \mathrm{O}_{3}$ Composite Nanoparticles," Materials Chemistry and Physics, Vol. 134, No. 1, 2012, pp. 407-411. http://dx.doi.org/10.1016/j.matchemphys.2012.03.009

[13] R. Arulmurugan, G. Vaidyanathan, S. Sendhilnathan and B. Jeyadevan, "Co-Zn Ferrite Nanoparticles for Ferrofluid Preparation: Study on Magnetic Properties," Physica BCondensed Matter, Vol. 363, No. 1-4, 2005, pp. 225-231. http://dx.doi.org/10.1016/j.physb.2005.03.025

[14] C. G. Granqvist and R. A. Buhrman, "Ultrafine Metal
Particles," Journal of Applied Physics, Vol. 47, No. 5, 1976, pp. 2200-2219. http://dx.doi.org/10.1063/1.322870

[15] L. L. Chen, J. Li, Y. Q. Lin, X. D. Liu, L. H. Lin and D. C. Li, "Surface Modification and Characterization of $\gamma$ $\mathrm{Fe}_{2} \mathrm{O}_{3}$ Nanoparticles Synthesized by Chemically-Induced Transition," Materials Chemistry and Physics, Vol. 141, No. 2-3, 2013, pp. 828-834.

[16] Q. M. Zhang, J. Li, H. Miao and J. Fu, "Preparation of Gamma- $\mathrm{Fe}_{2} \mathrm{O}_{3} / \mathrm{Ni}_{2} \mathrm{O}_{3} / \mathrm{FeCl}_{3}\left(\mathrm{FeCl}_{2}\right)$ Composite Nanoparticles by Hydrothermal Process Useful for Ferrofluids," Smart Materials Research, Vol. 2011, 2011, Article ID: 351072. http://dx.doi.org/10.1155/2011/351072

[17] A. R. Wang, J. Li and Y. Wang, "Analysis of $\mathrm{Fe}_{3} \mathrm{O}_{4}$ Nanoparticles Treated with $\mathrm{Fe}\left(\mathrm{NO}_{3}\right)_{3}$," Journal of Instrumental Analysis, Vol. 25, No. 6, 2006, pp. 35-38. (in Chinese)

[18] J. Li, X. Y. Qiu, Y. Q. Lin, X. D. Liu, R. L. Gao and A. R. Wang, "A Study of Modified $\mathrm{Fe}_{3} \mathrm{O}_{4}$ Nanoparticles for the Synthesis of Ionic Ferrofluids," Applied Surface Science, Vol. 256, No. 23, 2010, pp. 6977-6981. http://dx.doi.org/10.1016/j.apsusc.2010.05.009 